\title{
Research
}

\section{Beyond Regulations in Fisheries Management: The Dilemmas of the "Beach Recorders" Bwana Dikos in Zanzibar, Tanzania}

\author{
$\underline{\text { Maricela de la Torre-Castro }}^{1}$
}

\begin{abstract}
Institutions and organizations are considered key elements for the successful management of natural resources. However, much of the work in this field has focused mainly on regulations. This paper identifies other factors, i.e., normative, cultural-cognitive, and psychological, affecting institutional performance, management, and feedback. Using the case of Zanzibar, Tanzania, it is illustrated through the analysis of the Bwana Dikos, which are public officials placed in villages and landing sites for monitoring purposes, how a well-designed organization and clear regulations might be necessary, but not sufficient, to achieve successful management. Through triangulation of interviews, document reviews, and participant observation, it was found that four dilemmas, i.e., kinship, loyalty, poverty, and control, interfered with institutional performance, thereby decreasing efficiency. Poverty was the main driving factor explaining the Bwana Diko's performance, but loyalty elements crosscut the other dilemmas as well. Psychological aspects were important and deserve further research. The control dilemma refers to the institutional mismatches in spatial and cognitive terms. Lack of institutional replication at the proper spatial scales negatively affected the resilience of the whole institutional setting. Furthermore, the importance of embeddedness, coproduction, and windows of opportunities to improve the institutional setting and the poverty condition of the Bwana Diko is discussed. This paper shows that a broad view of institutions is urgently needed to understand the complexity of social-ecological systems, achieve sustainability goals, tackle development, and meet our fundamental challenge, poverty alleviation.
\end{abstract}

Key Words: common-pool resources; fisheries management; fisheries monitoring; institutions; institutional performance; regulations; resilience; social-ecological systems; Tanzania; Zanzibar.

\section{INTRODUCTION}

It is hardly controversial that institutions associated with natural resources are key factors for the success or failure of management alternatives (Ostrom 1990, Berkes and Folke 1998, Agrawal 2001, Holling 2001, Young 2002). It has been argued that institutions and/or organizations nested in multilevels of governance constitute a desirable structure to address natural resource management problems associated with common-pool resource situations (e.g., Ostrom 1990, Folke 1998, Holling 2001, Berkes 2002, Young 2002). Monitoring is a crucial element for management (e.g., Ostrom 1990, Berkes and Folke 1998, Danielsen et al. 2005), and constant information flows are needed to facilitate management and respond to change when needed (e.g., Berkes and Folke 1998, Anderies and Norberg, in press). Moreover, institutions associated with management of natural resources are not only linked to the ecosystem itself, but are embedded in the combined social-ecological system (SES), thus affecting and being affected by social and cultural institutions, human relationships, and the resource itself. Institutions are not simply related to resource management, but belong to the governance sphere (Dietz et al. 2003, Kooiman and Bavinck 2005).

Recent efforts addressing institutions for natural resource management have pointed out the need to include ecosystem dynamics (Folke et al. 1998, Brown 2003), consider nonequilibrium solutions (Anderies et al. 2004), introduce complexity and diversity approaches (Cumming and Norberg, personal communication), design flexible and open institutions and multilevel governance systems (e. g., Dietz et al. 2003), and to move beyond regulative 
elements of institutions into normative and culturalcognitive ones (Jentoft 2004, de la Torre-Castro 2006). It is in this recent effort that this work belongs.

In this study, I address the role of the beach recorders, hereafter Bwana Dikos, for marine resource management in Zanzibar, Tanzania. Bwana Dikos are public officials placed in coastal villages or landing sites, constituting a link and an intersection point between the social and ecological parts of the SES in Zanzibar, as well as the vertical and horizontal links of the organizational structure (Berkes 2002, Young 2002). The objective is to highlight, identify, and discuss problems linked to the Bwana Diko's role and functions, and how the difficulties that the recorders face in their everyday praxis, in turn, affect management performance. Through the dilemmas of the Bwana Diko,> I illustrate the importance of normative and culturalcognitive elements of institutions normally not addressed when dealing with common-pool resources. Most studies on common-pool resources have focused on rules in use (Imperial and Yandle 2005) or access, regulations, rights, and control over resources (Berkes 2005), and even in developing countries, most studies have followed rational choice approaches and institutional economics (Ostrom et al. 1993).

Here, I will present the dilemmas of the Bwana Diko, highlighting the normative and cultural elements of institutions (Scott 2001), and relate the dilemmas to the issue of organizational structure and associated institutions. I will briefly discuss the relevance of the embeddedness of public officials in wider social relationships (Evans 1996, discussed in Harriss 2002) for development. Ostrom (1996) addresses, in similar terms, coproduction, i.e., "coproduction implies that citizens can play an active role in producing public goods and services of consequence to them." I will briefly address vulnerability and decrease of resilience as a consequence of the lack of institutional replication.

My main argument is that a clear, nested organizational structure and well-established regulations might be necessary but not sufficient conditions for the "well" functioning and performance of the entire institutional setting. Using a particular institution, I argue that normative and cultural-cognitive institutional elements, cognitive capacities, psychological processes, and wider social and political contexts are factors affecting the entire institutional dynamics and the governance system.

\section{METHOD}

The essay is based on triangulation of interviews, analysis of documents, and participant observation. Data and materials were collected during a total of six field trips to Zanzibar, varying in duration between $1 / 2$ to $3 \mathrm{mo}$, during 2002-2005. Semistructured interviews at different occasions were held with fishermen $(N=37-48)$, seaweed farmers $(N=22-25)$, key informants $(N=15)$ and managers $(N=20)$ from the different ministries, especially the Department of Fisheries and Marine Resources (DFMR). Interviews with fisherman were held in Swahili using a translator, wheras those with managers took place in English. A comprehensive review of policy documents, legislation, and the historical files of the DFMR were done from 1992 to the present. Relevant information was also gathered during a participatory workshop held in Chwaka Bay, Zanzibar in 2004. About 100 people participated, including local fishermen and seaweed farmers, key informants, main government representatives, and scientists from Tanzania, the East African region, and Europe (de la Torre-Castro and Jiddawi 2005).

I lived in the villages and had daily contact with the Bwana Dikos. Formal and informal situations were shared. The formal situations were during interviews ( $N=10$, semistructured interviews) and workshop participation. I was also involved with the Bwana Dikos in collecting fish data in the local markets, thus having formal working meetings. We also had numerous informal talks and gatherings. During all the field trips, the participant observation method was used.

The information gathered was further analyzed and interpreted from an institutional perspective, focusing on the role of the Bwana Dikos in the organizational structure in Zanzibar, and the possible consequences for fisheries management. The analyses were done from the individual level to the whole organizational structure, focusing on Unguja, the largest island in the Zanzibar archipelago. 


\section{RESULTS}

\section{Zanzibar nested organization for marine resource management}

Zanzibar is an archipelago situated on the east coast of Tanzania, and together with the mainland forms the United Republic of Tanzania (URT). The URT is a unitary state, but Zanzibar has autonomy in nonunion matters including the management of marine resources. Union matters are mainly related to the Constitution, foreign affairs, defense, security, citizenship, etc. (Constitution of the URT 1977). The Revolutionary Government of Zanzibar with its different ministries governs the Islands. The Ministry of Agriculture, Livestock, and Environment (MALE) is situated at the highest level of organization in Zanzibar, followed by the Department of Fisheries and Marine Resources (Swahili: "Idara ya uvuvi na mazao ya baharini"), which deals with the management of all marine resources (DFMR 2005). At the district council level, the district fisheries office collaborates with the constituencies, wards, and "Shehias." The Shehia is the lowest local governance level, and is appointed by and accountable only to the Revolutionary Government and the respective villages and landing sites under its jurisdiction. At the next level, i.e., the local scale of a village and/ or a fish landing site, the Bwana Diko is the responsible institution (Fig. 1).

Although natural resource management issues are not considered a union matter, there is communication and coordination with the mainland and a common agreement trying to reach harmonization on organizational structures and management approaches, mainly in terms of deepsea fishing affecting the Exclusive Economic Zone (EEZ). The nested organizational design in Zanzibar has been considered successful and desirable for the URT (e.g., Ruitenbeek et al. 2005, DFMR Director 2005, personal communication).

The regulative institutions are defined by a set of laws, Acts, and policy documents. In Zanzibar, the most important are the Fisheries Act of 1988, the Fisheries Law of 1993, the newly revised Fisheries Act of 2005, not yet passed, and a policy document providing guidelines for fisheries. In general, fisheries in Zanzibar are diverse, e.g., type of gears, fishing techniques, and habitat use, and mainly artisanal, i.e., performed close to the shore and with relatively low technology. Foreign vessels are licensed for Exclusive Economic Zone operation. In the artisanal fisheries sector, the primary management strategies include gear restriction, marine protected areas, and limitation of fishing techniques. Monitoring and communication is carried out by a number of public officials placed in the different villages or landing sites, known as beach recorders, Bwana Dikos in Swahili.

\section{The Bwana Diko institution}

In the organizational structure (Fig. 1), Bwana Dikos are the link between the formal administrative units and the local resource users. They are individuals, but they also constitute a formal institution. The Bwana Diko is in charge of a village or a landing site, and the two units do not always overlap. Bwana Dikos are the main agents of the monitoring system in the local communities for marine resources in the Islands. They are the only monitoring agents that have daily direct contact with the resource users, and the information provided by them is crucial for gaining knowledge of the system and as basis for decision making. There are 85 Bwana Dikos in Unguja and 27 in Pemba. However, extensive data collection, including data on fish landings, takes place in only 19 locations in Unguja and 12 in Pemba (DFMR 2005, Bwana Dikos, interviews.). The locations in Unguja are shown in Fig. 2.

The main duties of the Bwana Dikos are to monitor artisanal fishing and seaweed farming activities and to enforce the respective laws. They record basic information on fishermen, e.g., age, boats owned, licenses, and the like. They check the seaworthiness of the boats and the legality of gears. Bwana Dikos also report accidents in the sea. They communicate changes in laws or policies, coming projects, planning issues, etc. from the Department of Fisheries and Marine Resources (DFMR) to the locals, and from the locals to higher organizational levels. Other issues such as the behavior of users, unusual events, or changes in attitudes and opinions of the local population are also reported (DFMR 2005, Bwana Dikosand Fishermen interviews).

In the selected locations for fish landing monitoring, Bwana Dikos record statistics of the local fishery every second day, each month. These records include number of fishermen, vessel type, time of landing, main species caught, weight of the catch, local market prices, i.e., mainly through auction, 
Fig. 1. The nested organizational structure for the management of marine resources in Zanzibar, Tanzania.

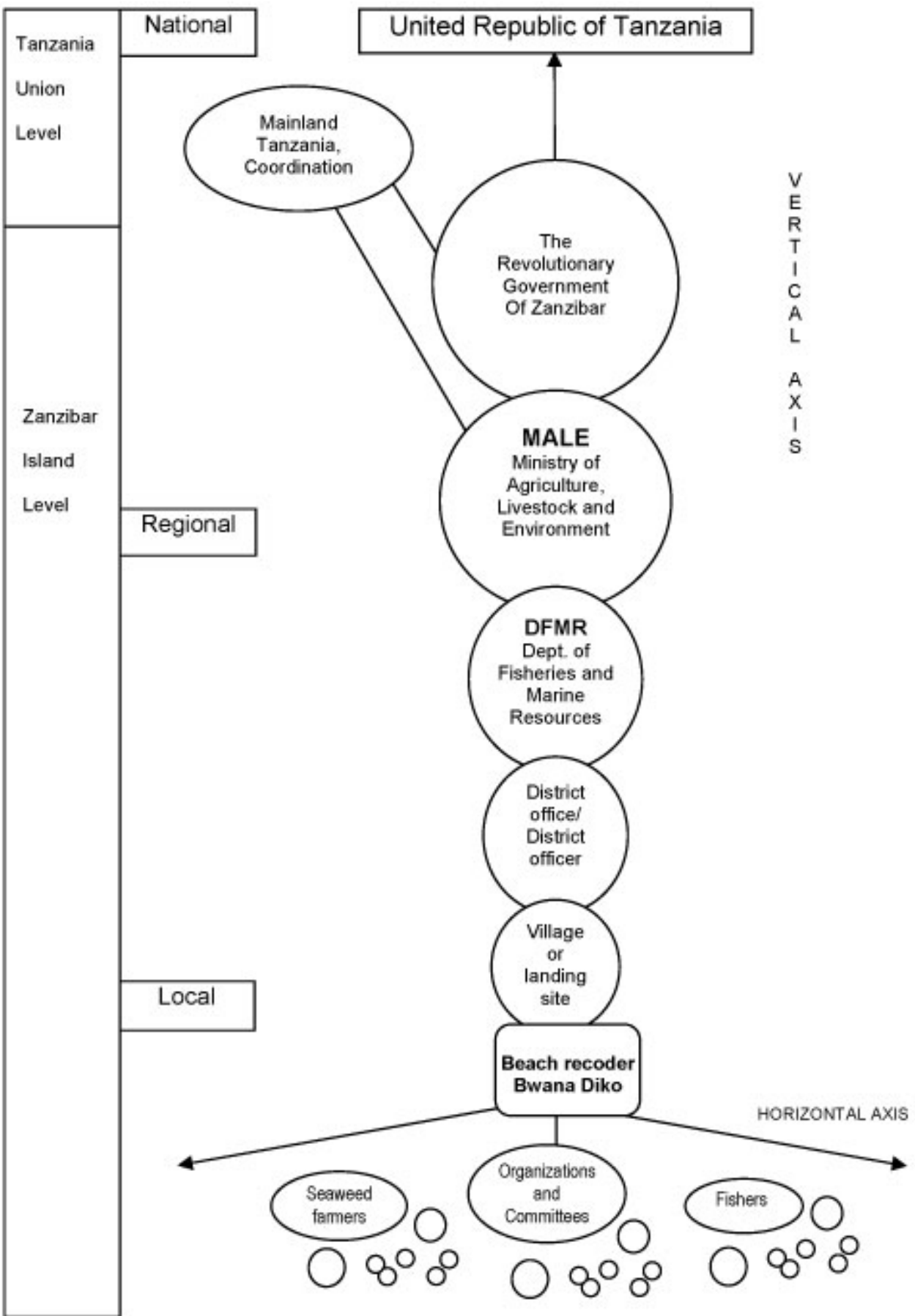


Fig. 2. Villages in which Bwana Dikos are placed and extensive data collection takes place.

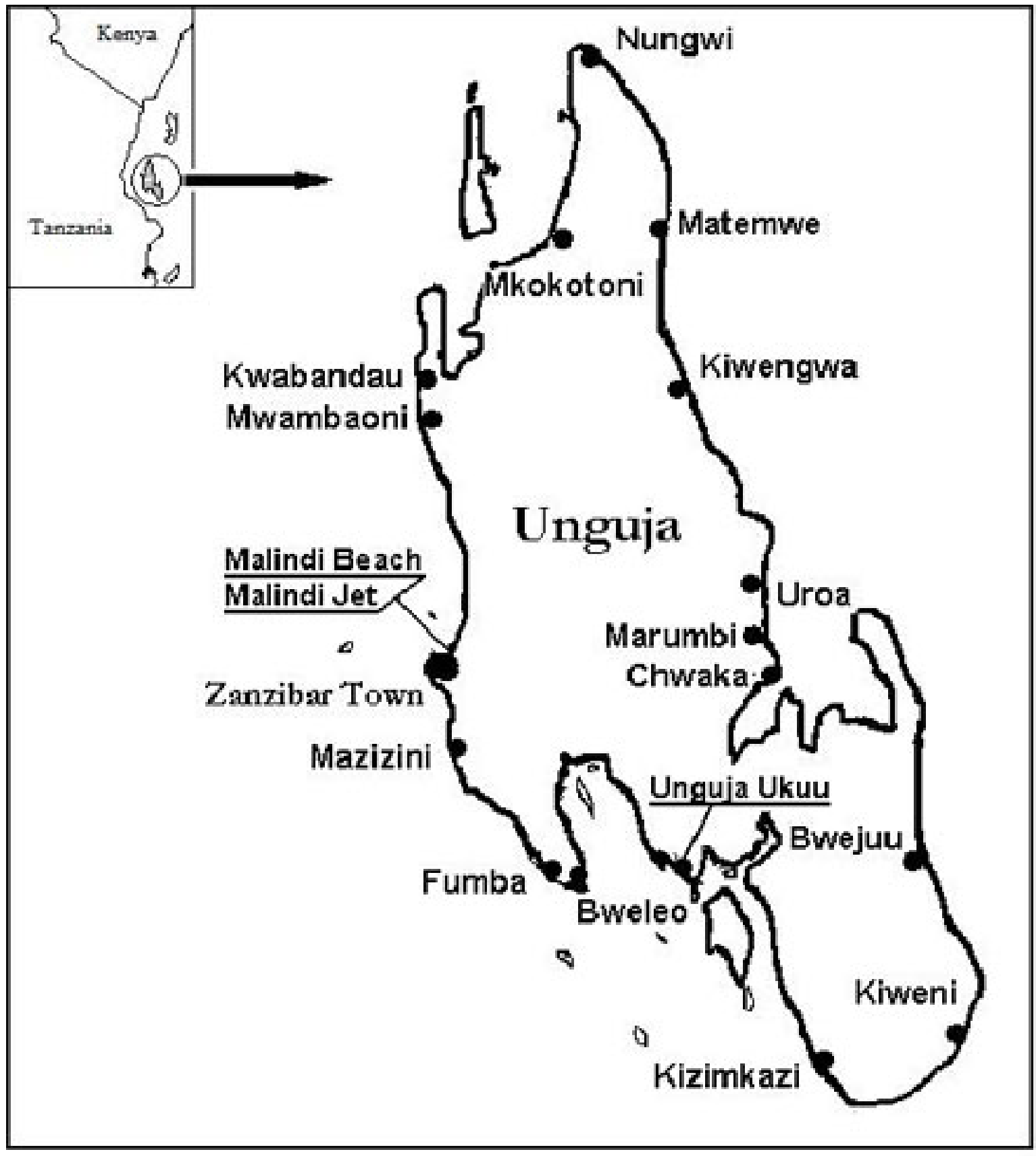


and tidal and weather conditions, as well as unusual events (DFMR 2005, Bwana Dikos, interviews, Jiddawi and Stanley 1999). They are formally in charge of monitoring, controlling, and reporting seaweed farming activities. However, the beach recorders are mainly focused on the monitoring of fisheries activities, the seaworthiness of fishing vessels, and the legality of gears (DFMR 2005, Seaweed farmers and Bwana Dikos interviews, personal observation).

The recruitment of a Bwana Diko is the responsibility of the DFMR, Zanzibar. There are only a few requirements to get the position. The first is to have an educational level that allows for training; normally secondary level. The second is that they should come from the same community in which they are going to work. A vast majority of Bwana Dikos are men, but few exceptions do exist, e.g., two women have been reported. The salary offered is about 50,0007-55,000 TZS/mo (1 USD $=1215$ TZS March 2006, DFMR).

The Bwana Diko institution has fundamental elements required to function successfully. It is nested into higher levels of organization responding to administrative units according to scale. The institution is articulated with a set of rules and regulations for monitoring and reporting and it is an essential part of the organizational structure. The institution also constitutes a formal communication channel cutting through important levels of the whole organizational structure, i.e., local, district, and central Zanzibar. This enhances the capacity to avoid common institutional failures due to lack or time-lags of information. The Bwana Diko has the possibility to report important issues and events rapidly, both horizontally and vertically. This is fundamental for the provision of rapid feedback in case of changes in the social-ecological system and opens up the possibilities for both co-management and adaptive management. Learning processes need constant monitoring and evaluation (Folke 2003).

Given the initial possibilities for good institutional performance, an important question is what can lead to decreased performance? What are the problems of the individual Bwana Dikos when performing their work in the local villages? How do these problems affect marine resource management in Zanzibar? In the following section, I will present four dilemmas that were identified during the field work.

\section{Dilemmas of the Bwana Diko}

\section{Kinship dilemma}

The arguments that the DFMR put forward to appoint a member of the same village or landing site are important and valid. The Bwana Diko will not need transport, will be available at all times, and will have easy access to the people, vessels, landing site, local market, etc. In short, a local person facilitates activities and reduces associated transaction costs, i.e., monetary and/or time-wise. Other arguments are the knowledge of the local community, both in terms of recognizing the fishermen and the seaweed farmers in the village and their organizations, as well as ecological knowledge associated with marine activities, e.g., knowledge of the local ecosystems, fishing grounds, species, fishing gears, techniques, etc. However, this is a double-edged sword, and the trade-off involved might be substantial. On one hand, such local knowledge might promote better performance in terms of accuracy in the registration of the users and resources, being a member of the community, whereas it paves the way for problems associated with reciprocity, friendship, kinship, and other social-capital related issues.

During interviews, and through participant observation, it was found that the Bwana Dikos had difficulty dealing with kinship relationships. How can the Bwana Diko report anything negative about a fisherman that is a relative and brings fish to his/ her household? How can they report their brothers, sisters, or uncles to the authorities? How can they report their wives? How can they interfere in the most important economic activity of the fellow members in the village, in a context of extended family, Swahili bands, religious norms, lack of opportunities, and general poverty?

The normal reaction is not to take action. It was clear from the interviews, conversations, and observations that a deep understanding of the context and a situation of both judge and being judged normally blocked the flow of information and the kinship dilemma was handled by favoring kinship relationships and giving priority to the short term benefits rather than long term consideration of maintaining productive ecosystems. The following quote illustrates the dilemma "I know that some activities and gears are damaging (the substrate)... but I cannot report them (their relatives)... what are 
they going to do for a living then? It is the only job that my family has" (Bwana Diko, interviews).

\section{Loyalty dilemma}

As members of the community, the Bwana Diko expressed that they are always facing the problem of to whom should they be loyal? Is it the village, $i$. e., their people, or is it their employer/organization? This situation is aggravated when directives, bylaws or projects are communicated or implemented and the local population might experience lack of possibilities to participate. Issues of legitimacy might arise and the Bwana Diko finds it difficult, in terms of internal psychological processes, to decide which side to take. The common situation is to solve the dilemma playing a double role. In the village they side with the villagers, whereas in the DFMR they side with their superiors. The loyalty dilemma leads to confusion and unclear communication. The Bwana Diko may not be able to act as a carrier of information in both directions. There are examples in which the local population does not agree with a certain project or regulation, but the Bwana Diko is not able to transmit the information and associated opinions because he feels that he is not loyal to the project and the DFMR, which in turn, produces guilt feelings toward the villagers (Bwana Dikos, interviews.). "They don't agree with the project (the villagers)...but I am afraid of retaliation (if I inform the Dept. of Fisheries)" (Bwana Diko, interviews). At the same time they feel like "bad" employees who cannot live up to the demands of the employer/ organization. The dilemma is in some cases solved by a "play theater" in which the Bwana Diko "behaves" and/or "plays" different roles according to the situation and who is she/he talking with. In such a situation, "realities" and opinions are masked, information is distorted, and flows are discontinuous (DFMR 2005, Managers from the different Departments, Fishermen and Seaweed Farmers' interviews, Bwana Dikos interviews, personal observation).

\section{Poverty dilemma}

The general, poverty faced by most countries of the Western Indian Ocean is crucial. In the case of the Bwana Diko it is expressed mainly in two ways: the poverty of the Bwana Dikos themselves, with a salary that cannot fulfill their and their family needs, and the poverty that most fishing villagers experience. In the coastal villages of Tanzania, about $85 \%$ of the population survives on less than
$\$ 1 / d$ (Ruitenbeek et al. 2005). The salary of the Bwana Diko of about $1700 \mathrm{TZS} / \mathrm{d}$ is low compared, for example, with the average fisherman income of about $2200 \mathrm{TZS} / \mathrm{d}$, and about $3000 \mathrm{TZS} / \mathrm{d}$ for basket traps fishermen (de la Torre-Castro, unpublished data, see also de la Torre-Castro and Rönnbäck 2004). To be a poor Bwana Diko has multiple consequences, at both individual and collective levels. At the individual level, it forces the Bwana Diko to search for additional income-generating activities. In the absence of monitoring of his own activity, he may be able to engage in other economic activities at any time, even during his working hours as a beach recorder. For example, during the mangrove cutting days, they may leave their jobs and try to earn some complementary income. The consequences of this situation are evident. The situation at the collective level might be even more serious. The poverty that most fishermen experience, combined with the Bwana Dikos' understanding of the situation, make them less prone to report irregularities and more prone to mask them. Overcoming poverty and bringing food for the day are the self evident objectives of all marine activities. The combination of poverty and a job including monitoring actions bring "short term losers" or "cheaters" into focus, and the situation for the Bwana Diko may be extremely difficult and painful. Under these circumstances cheating becomes the norm. The poverty dilemma may be solved by forming alliances with the community members, allowing for activities that bring daily income irrespective of the regulations, and giving priority to day-to-day income generating activities rather than future options that might be uncertain.

\section{Control dilemma}

The control dilemma refers to the question of how a single human can keep control over all the factors involved in monitoring the fisheries dynamics and to keep records at the same time. The single person responsibility is due to the lack of resources, mainly economic but sometimes also human, since in some villages it might be difficult to find persons with the level of education required. The Bwana Diko is in charge of the whole landing site, associated fishermen, fisheries, and seaweed farming activities, and cannot control the events happening in the entire SES. The cognitive capacities of a human being are insufficient for that task. Moreover, the so called "mismatch" between the institution and the scale is present in various degrees depending on the size of the landing site and the 
extension of the fishing area to monitor. There are cases, for example the Chwaka landing site, in which a single Bwana Diko has to monitor up to 50 $\mathrm{km}^{2}$. Monitoring in the water is almost impossible since the Bwana Diko does not have a boat at his/ her disposal, and it is almost solely performed by the Coast Guard, which also helps controlling illegal fishing. The lack of resources and the limitations for a single person are extremely difficult to overcome. While gathering data in the local markets, the Bwana Diko has to check all fishermen coming from the seashore, weigh the catch, take notes, and keep track of all the batches in the auction to record their value. A minimum of three to four persons has been suggested to collect data correctly at the local fish markets (Jiddawi and Stanley 1999).

The control dilemma can be expressed as a mismatch between the cognitive capacities of an individual and the expected requirements, both in spatial terms and at the level of complexity of the assignments, i.e., the capacity to perform a number of different tasks at the same time. The control dilemma is solved by an internal system of priorities. Priorities are given according to the previous dilemmas, i.e., kinship, loyalty, and poverty, but highest priority is given to everyday survival. In this situation, the Bwana Dikos know that they cannot possibly fulfill their tasks as required, they know their own limits and capacities and they keep on performing their work "as best as they can" (Bwana Dikos, interviews).

Figure 3 shows the key position of the Bwana Diko and how the four dilemmas might constrain performance and/or open up possibilities if they are removed or minimized. Table 1 shows possible effects of the dilemmas on some of the work tasks of the Bwana Dikos.

\section{DISCUSSION}

It is apparent that the distinction between the three first dilemmas, kinship, loyalty, and poverty is only analytical. In reality, all elements are fused. All three dilemmas have a loyalty element involved, or in other words, the loyalty dilemma is expressed in different ways. The poverty situation is, however, the clear cause of the dilemmas. The last dilemma, control, has to some extent a different character and refers to spatial vs. cognitive mismatches. In practical ways it can be expressed as how well a single person can monitor complex situations and perform numerous tasks with few resources.

The main point of this work is that a good organizational structure and clear formal institutions such as rules and regulations are necessary but not sufficient to achieve good performance and efficient management, to facilitate information flow, to act as a bridging institution between the formal setting and the resource users, or even to perform the work assignments associated to the different organizational levels.

Institutional and organizational structures for natural resource management in Tanzania have been considered robust and prepared for the challenges of the future (e.g., DFMR 2005, Ruitenbeek et al. 2005). The organizational structure for fisheries management in Zanzibar is considered a model for the mainland, due to the well designed structural elements (DFMR Director 2005, personal communication). Although this may be true in many senses, a deeper analysis and precautionary approaches considering participation should be contemplated, especially when implementing new initiatives and facilitating new large scale investments. Much will be gained by analyzing other aspects than just structures. Contextual issues and social practice with the whole spectrum of institutions associated with human behavior, e.g., regulations, norms, social and cultural institutions, as well as the psychological aspects and cognitive capacities of the individuals taking part in decision making will provide a more comprehensive analysis. Together, these analyses will give insights for improving and understanding management performance (see also Young 2002, McCay 2002, Folke 2003, Jentoft 2004).

The management of marine resources is highly complex and characterized, among other things, by extremely high levels of uncertainty (e.g., Ludwig et al. 1993, Hughes et al. 2005, Sheffer et al. 2005) and chaotic behavior (Acheson and Wilson 1996). Managers are always facing the problem of taking decisions and creating policies with incomplete information. The complexity and multivariate character of the marine systems and associated fisheries' problems force managers to simplify and subtract dimensions in order to tackle problems (Anderies and Norberg, in press). The information provided by the Bwana Dikos is crucial, since in many cases it is the only information available for decision making, providing the only possibility to 
Fig. 3. Position of the Bwana Dikos and the dilemmas in the organizational structure, indicating links and feedbacks between elements.

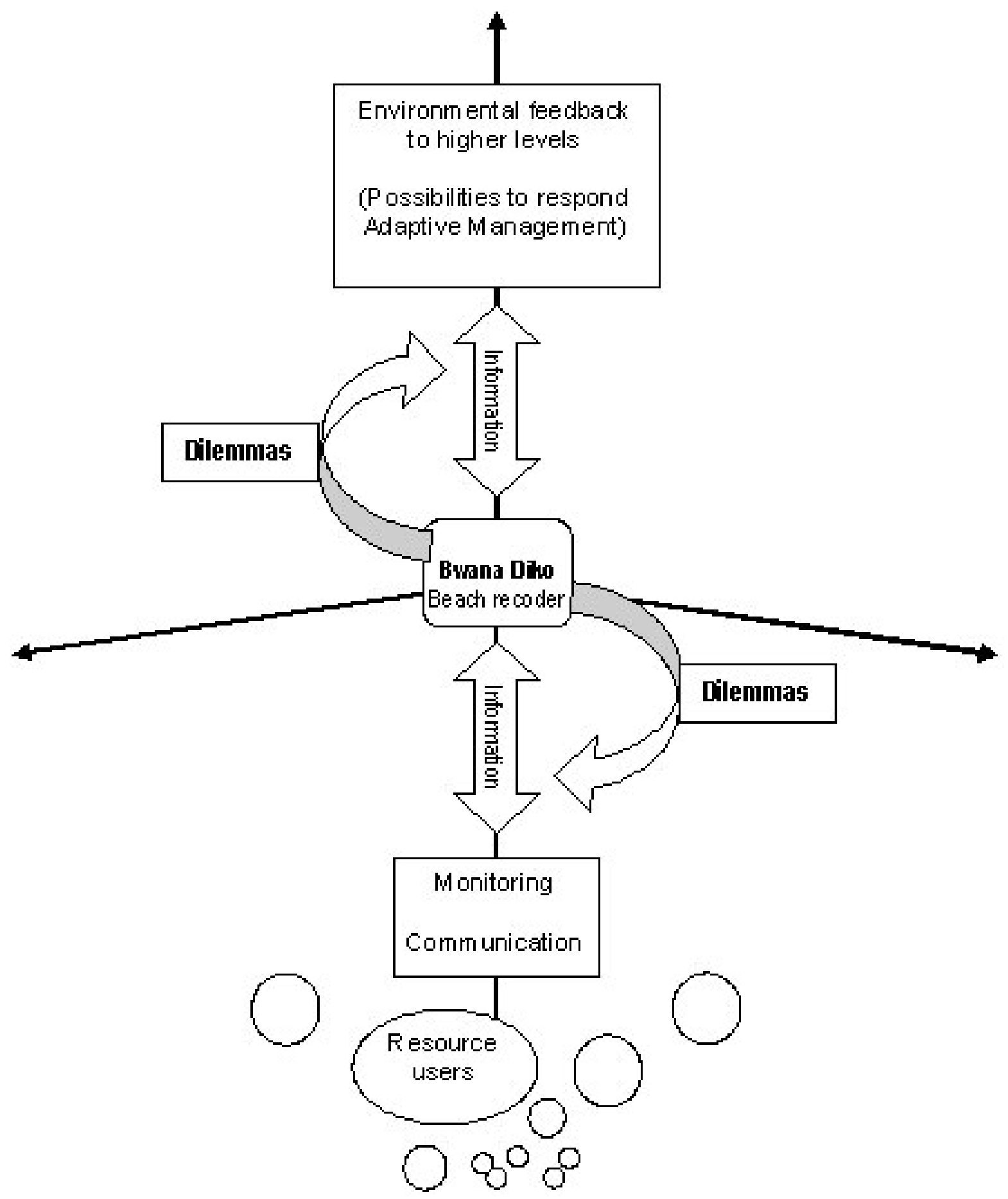


Table 1. Examples of interactions between the dilemmas and selected monitoring tasks of the Bwana Dikos. Kinship in this context extends to all members of the extended family and includes also multiple marriage and secret relationships.

\begin{tabular}{|c|c|c|c|}
\hline $\begin{array}{l}\text { Dilemmas } \\
\text { /tasks }\end{array}$ & Kinship dilemma & Loyalty dilemma & Poverty dilemma \\
\hline \multirow[t]{2}{*}{$\begin{array}{l}\text { Report illegal } \\
\text { fishing gears } \\
\text { and/or techniques }\end{array}$} & $\begin{array}{l}\text { Might avoid to report } \\
\text { family members to the } \\
\text { authorities }\end{array}$ & $\begin{array}{l}\text { Avoids to report } \\
\text { members of their own } \\
\text { villages }\end{array}$ & \multirow{2}{*}{$\begin{array}{l}\text { Might allow illegal } \\
\text { methods or activities } \\
\text { because of } \\
\text { understanding of the } \\
\text { poverty situation in the } \\
\text { village }\end{array}$} \\
\hline & $\begin{array}{l}\text { Masked the magnitude } \\
\text { of illegal fishing }\end{array}$ & $\begin{array}{l}\text { Masked the magnitude } \\
\text { of illegal fishing }\end{array}$ & \\
\hline
\end{tabular}

License control and report
Might ignore payment from family members

Loss of state income mainly affecting DFMR conservation, education and scientific projects

Communication about plans and projects

Might favor family members
Masked or incomplete information

Not communicating controversial opinions

Report and check Masked information of seaworthiness of boats in bad conditions the boats belonging to family

Masked the status of artisanal fisheries infrastructure

Market data collection as basis for statistical analysis and fisheries management
Not reporting illegal species caught in the members or friends village

Masking the success of management efforts

Not reporting illegal
Ignore payment from their own villages

Loss of state income mainly affecting DFMR, conservation, education and scientific projects

Pressures when patronclient relationships are present

Impossibility to communicate negative opinions/feelings of the locals to the authorities and vice versa

Masked information of boats in bad conditions in the village

Might increase accidents Subject for pressure in the village species consumption in particular sectors of the population

Masking the success of management efforts
Ignoring payments in general

Loss of state income mainly affecting DFMR, conservation, education and scientific projects

Might favor own village Masked or incomplete information to both locals and authorities

Might favor individuals for credits causing internal conflicts patron-client relationships and or reciprocity favors

Occasionally leaving data collection activities and engage into more lucrative opportunities

\section{Control dilemma}

Impossibility to monitor due to large size of the areas

Knowledge reported to the authorities is fragmentary and/or misleading

Constraints the accuracy of controls

Problems to ensure that the whole community has been informed

Difficult to find proper arenas for communication

Limit the frequency and accuracy of the possible observations and controls

Impossibility to monitor all activities in water and market

Misleading and/or incomplete statistical data Missing data, leading to underestimation of total catches in biomass and monetary terms, incomplete information in all reported parameters Loss of statistical power and balanced designs 
build up records to take management decisions at present and to deepen the historical understanding of the system. This information might be the only possible way to reduce uncertainty, since at least some basic variables will be estimated, e.g., catch biomass, species composition, seasonal variations, fishers population structure, and local users' perceptions. Furthermore, the role of the Bwana Dikos can be critical for the success of the entire system, since the management situation is compounded by scarcity of scientific and administrative resources. At the same time, the potential uses are multifaceted and open up for analysis at higher organizational levels, e.g., research section of the Department of Fisheries and Marine Resources (DFMR), that might include complexity and uncertainty, e.g., Bayesian approaches, resilience management, scenario building, modeling, and complex adaptive systems frameworks (see also www.resalliance.org/).

Moreover, with the Bwana Diko embedded in the wider cultural and social setting as well as in the state apparatus, synergistic effects, i.e, a better performance of the state organization working together with the citizens, may be produced (Pomeroy and Berkes 1997, Evans 1996, Ostrom 1996, Carlsson and Berkes 2005).

In an African fisheries context, the key role of the government has been pointed out by some authors (e.g., Nielsen et al. 2004), and empirical studies of subsistence fisheries found that comanagement is generally perceived as successful (Napier et al. 2005). Other comanagement efforts in East Africa have yielded varied results, but in general, comanagement through state involvement considering bottom-up participation is considered the way ahead (e.g., Francis and Bryceson 2001, Ruitenbeek et al. 2005, WIOMSA 2005).

However, the embeddedness of public officials should be considered carefully since it is not always successful. The wider social, political, cultural, and economic conditions might be determinant. Taking irrigation as an example, irrigation officials in India do not belong to their own communities and are constantly shifted to avoid patron-client relations and corruption in an environment in which, for different complex reasons, those relations have flourished (see Harriss 2002). In contrast, the irrigation case of Taiwan (Lam 1996) shows that in egalitarian systems it is possible to have locals creating synergy and striving for equity and sustainability. Other cases from South Korea show similar patterns (Harriss 2002).

Little empirical work on institutional aspects related to management has been conducted in Zanzibar (but see Myers 2002, Andersson 2004, de la TorreCastro 2006). However, power politics have been part of a long history in a merchant society with various external powers dominating. After the revolution in 1964, the search for identity and struggles of the poor have been expressed in party politics (Mazrui and Noor Shariff 1994) that might play a role for the embeddedness and patron-client relationships.

In the case of marine resource management in Zanzibar, an approach similar to the Indian case, in which public officials are not serving in their home towns, seems to be a possible solution, which can be tested by the Department of fisheries. Recent changes in fisheries policies, i.e., a new proposal for Fisheries Act 2005, under revision, and legislation from the Environmental Management for Sustainable Development Act (1996) toward community participation and comanagement possibilities by letting the local entities delineate their management plans, encouragement of the formation of fishers' committees, and seeking for sustainable solutions with local participation when creating Marine Protected Areas (MPA) are all windows of opportunities (Olsson et al. 2004) to create synergies.

Danielsen et al. (2005) address locally based monitoring with cases from all over the world. They show that a crucial factor for improving results is the institutionalization of any kind of monitoring efforts. Without the involvement of the state and the consideration of national policies and goals, projects are less likely to succeed. However, when state agencies are involved in corruption and rentseeking, bottom-up initiatives may improve monitoring.

In Zanzibar, the crucial steps of institutionalization of monitoring and the development of regional policies have been already taken, so there is an opportunity to move into novel approaches. In a context of poverty and constant struggle, Bwana Dikos may also fulfill a function of empowerment for the local fishers and seaweed farmers by listening to their demands and transmitting information (see Jentoft 2005, for a discussion on empowerment). In an African context see for 
example, Nielsen et al. (2004) and Obura et al. (2002). The Bwana Dikos can act as a legitimate link between the community and the government agency provided that the right incentives for government collaboration are clear and attractive, e.g. higher salaries, arenas for discussion, prizes, etc. In Taiwan, irrigation officials have been positively stimulated by incentives such as provision of an annual bonus, promoting a sense of high status among the officials, and the possibility of lifetime carriers (Lam 1996). Another aspect, which must be considered cautiously, involves participatory processes in the election of the Bwana Diko. The environmental committees of the villages and the newly promoted fishermen committees by the DFMR can facilitate and legitimize the process.

Although kinship institutions are extremely stable and difficult to change, and poverty alleviation is one of our biggest challenges, there are, however, some relatively straightforward ways to tackle the dilemmas. The wage issue is not trivial and reforms allowing increases will certainly lead to a better performance. The control dilemma reflects institutional insufficiency in terms of spatial mismatches, cognitive mismatches and lack of replication. The spatial scale is normally too large for one individual and this single individual situation poses cognitive problems and increases vulnerability in the institutional performance. When the individual fails, e.g., in case of sickness, the whole institution fails, at least temporarily. No monitoring takes place, data records are interrupted, and communication stops. This shows the importance of institutional mismatches for resilience in the system. A simple increase in the number of Bwana Dikos according to spatial scales and well-defined areas of responsibility would contribute to higher resilience. It is worth remembering that higher institutional diversity is not always positive and may increase costs in other areas such as coordination costs (e.g., Norberg et al., personal communication). In this case, it is not an increase of diversity that is needed, rather the same Bwana Diko institution can be improved by increasing the number of individuals. This replication might however, also increase the cost of communication and transfer of information between a larger group of Bwana Dikos and further through the vertical axis as well as the risk for conflicts, competition, and power issues among them. de la Torre-Castro (2006) illustrated how different institutional elements, i.e., regulations, norms, and cultural aspects have led to conflict and tension in Chwaka Bay, Zanzibar.

The interviews with different Bwana Dikos suggest that psychological factors and internal motivation play an important role in their everyday work. Social pressures, the complexity and extent of the kinship relations, and their intersection in the organizational structure deeply affect the Bwana Dikos. It is beyond the scope of this study to deal with these issues. However, this study shows their major relevance and the need to be considered in future research. The importance of psychological perspectives and the separation between disciplines dealing with institutional approaches to understand human behavior and further institutions have been pointed out (e.g., Ostrom 2003). As Jentoft (2005, p.2) argues "social and natural sciences do not provide all knowledge it takes to build co-management", education, and psychological factors are as relevant. Peterman (2004) draws attention to cognitive psychology to improve communication about uncertainties between stakeholders dealing with fisheries. Furthermore, the scale vs. cognitive mismatch has not been given adequate attention.

\section{CONCLUSIONS}

Bwana Dikos, public officials placed in villages or landing sites, constitute a key intersection point in the social-ecological system of the fisheries of Zanzibar. They also constitute links between formal and informal spheres, they are key structures in the vertical and horizontal axes, they represent the possibility to learn from the system through constant and good quality data acquisition, and they can be an invaluable source of information on the actual situation and legitimate bottom-up issues of the local population. The existence of the four dilemmas: kinship, loyalty, poverty, and control seriously jeopardizes the flow of the extensive knowledge that the Bwana Dikos actually have, and reduces the effectiveness of the formal governance systems for coastal fisheries management.

Focusing on the performance of these critical institutions will provide insights into the understanding of the dynamics of social-ecological systems and improve management. Bwana Dikos are the carriers of information to higher vertical levels opening up the possibilities to respond to environmental feedbacks. Bwana Dikos are the 
most important agents that link local coastal communities to higher levels, thus constituting key elements in the organizational and institutional structures for marine resource management. Addressing these aspects with a combined focus on poverty reduction strategies and the possibility to increase the number of beach recorders/landing site is fundamental for the improvement of institutional performance and the monitoring of marine resources in Zanzibar and in similar settings.

This paper underscores the need for a "thick" approach in understanding institutions as a consequence of social practices in a broad sense (Young 2002, McCay 2002), considering a wider sociocultural approach (Folke 2003) and to move beyond regulation into normative and cultural elements (e.g., Jentoft 2004, de la Torre-Castro 2006).

Responses to this article can be read online at: http://www.ecologyandsociety.org/voll1/iss2/art35/responses/

\section{Acknowledgments:}

Thanks to the people of Zanzibar and the Bwana Dikos who openly shared information. To the Department of Fisheries and Marine Resources (DFMR) and the Institute of Marine Sciences (IMS) Zanzibar for constant support. To Musa A. Jumbe, Makame Nassor, Saleh Sadiq Osman, Hamad Khatib, and Juma Omar Haji from DFMR for continuous help. Thanks to Narriman Jiddawi (IMS) for constant collaboration. Thanks to Carl Folke, Nils Kautsky, Patrik Rönnbäck, Jon Norberg, Ali H. Kombo, Issa A. Suleiman, and Peter Shunula for all feedback. Thanks for all the comments and suggestions from the anonymous reviewers and the Subject Editor, which enriched the manuscript. This work was funded by the Swedish International Development Cooperation Agency (SIDA).

\section{LITERATURE CITED}

Acheson, J. M., and J. A.Wilson. 1996. Order out of chaos: the case for parametric fisheries management. American Anthropologist, New Series 98:579-594.
Agrawal, A. 2001. Common property institutions and sustainable governance of resources. World Development 29:1649-1672.

Anderies, J. M., M. A. Janssen, and E. Ostrom. 2004. A framework to analyze the robustness of social-ecological systems from an institutional perspective. Ecology and Society 9(1):18. [online] URL: http://www.ecologyandsociety.org/vol9/iss1/ $\underline{\operatorname{art18}}$.

Anderies, J. M., and J. Norberg. In press. Observing, understanding, and acting: information processing for navigating social-ecological systems. Norberg, J. M. and G. S. Cumming, editors. Complexity theory for a sustainable future. Columbia University Press, New York, New York, USA.

Andersson, J. 2004. Welfare environment and tourism in developing countries. Dissertation. Gothenburg University, Gothenburg, Sweden.

Berkes, F. 2002. Cross-scale institutional linkages: perspectives from the bottom up. Pages 293-321 in E. Ostrom, T. Dietz, N. Dolšak, P. C. Stern, S. Stovich, and E. U. Weber, editors. The drama of the commons. National Research Council Committee on the Human Dimensions of Global Change, Division of Behavioral and Social Sciences and Education. National Academy Press, Washington, D.C., USA.

Berkes, F. 2005. Commons theory for marine resource management in a complex world. Senri Ethnological Studies 67:13-31.

Berkes, F., and C. Folke, editors. 1998. Linking social and ecological systems: management practices and social mechanisms for building resilience. Cambridge University Press, Cambridge, UK.

Brown, K. 2003. Integrating conservation and development: a case of institutional misfit. Frontiers in Ecology and Environment 1:479-487.

Carlsson, L., and F. Berkes. 2005. Comanagement concepts and methodological implications. Journal of Environmental Management 75:65-76.

Danielsen, F., N. D. Burgess, and A. Balmford. 2005. Monitoring matters: examining the potential of locally based approaches. Biodiversity and 
Conservation 14:2507-2542.

de la Torre-Castro, M. 2006. Humans and seagrasses in East Africa: a social-ecological systems approach. Dissertation. Department of Systems Ecology, Stockholm University, Stockholm, Sweden.

de la Torre-Castro, M., and N. S. Jiddawi. 2005. Seagrass related research and community participation: "fishermen, fisheries and seagrasses." Participatory workshop. Chwaka Bay, Zanzibar, Tanzania, 6-11 September, 2004. Western Indian Ocean Marine Science Association (WIOMSA), Book Series Number 3. WIOMSA, Zanzibar, Tanzania.

de la Torre-Castro, M., and P. Rönnbäck. 2004. Links between humans and seagrasses: an example of tropical East Africa. Ocean and Coastal Management 47:361-387.

Department of Fisheries and Marine Resources (DFMR). 2005. Fisheries Act. Zanzibar, Tanzania.

Dietz, T., E. Ostrom, and P. C. Stern. 2003. The struggle to govern the commons. Science 302:1907-1912.

Evans, P. 1996. Government action, social capital and development: reviewing the evidence on synergy. World Development 24:1119-1132.

Folke, C. 1998. Ecosystem approaches to the management and allocation of critical resources. Pages 313-345 in M. Pace and P. Groffman, editors. Successes, limitations and frontiers in ecosystem science. Springer, New York, New York, USA.

Folke, C. 2003. Social-ecological resilience and behavioural responses. Pages 226-242 in B. Hansson, A. Biel, and M. Mårtensson, editors. Individual and structural determinants of environmental practice. Ashgate, Aldershot, UK.

Folke, C., L. Pritchard Jr., F. Berkes, J. Colding, and U. Svedin. 1998. The problem of the fit between ecosystems and institutions. International Human Dimensions Programme on Environmental Change (IHDP) Working paper Number 2.

Bonn, Germany. Available online at: http://www.ih dp.uni-bonn.de/html/publications/workingpaper/wp0102. htm.
Francis, J., and I. Bryceson. 2001. Tanzanian coastal and marine resources: some examples illustrating questions of sustainable use. Pages 76-102 in J. Ahmed, C. Bergstrøm, I. Bryceson, B. Child, J. Francis, P. Khan, B. G. Ousmane, T. L. Price, S. Senaratna, N. Tareen, and C. van Dam, editors. Lessons learned: case studies in sustainable use. IUCN, Gland, Switzerland.

Available online at: http://www.iucn.org/themes/ssc/ susg/docs/francis.pdf.

Government of Tanzania. 1996. Environmental Management for Sustainable Development Act. Zanzibar, Tanzania.

Government of Tanzania. 1988. Fisheries Act Number 8. Zanzibar, Tanzania.

Government of Tanzania. 1993. Fisheries Law. Zanzibar, Tanzania.

Harriss, J. 2002. Depoliticizing development: the World Bank and social capital. Anthem, London, UK.

Holling, C. S. 2001. Understanding the complexity of economic, ecological, and social systems. Ecosystems 4:390-405.

Hughes, T. P., D. R. Bellwood, C. Folke, S. S. Steneck, and J. Wilson. 2005. New paradigms for supporting the resilience of marine ecosystems. Trends in Ecology and Evolution 20:380-386.

Imperial, M. T., and T. Yandle. 2005. Taking institutions seriously: using the IAD framework to analyze fisheries policy. Society and Natural Resources 18:493-509.

Jentoft, S. 2004. Institutions in fisheries: what they are, what they do, and how they change? Marine Policy 28:137-149.

Jentoft, S. 2005. Fisheries co-management as empowerment. Marine Policy 29:1-7.

Jiddawi, N. S., and R. Stanley. 1999. Fisheries stock assessment in the traditional fishery sector: the information needs. In Proceedings of the National Workshop on the Artisanal Fisheries Sector, 22-24, September 1997, Zanzibar, Tanzania. Institute of Marine Sciences, University of Dar es Salaam, Zanzibar, Tanzania. 
Kooiman, J., and Bavinck, M. 2005. The governance perspective. Pages 11-24 in J. Kooiman, M. Bavinck, S. Jentoft, S., and R. Pullin, editors. Fish for life: interactive governance for fisheries. Amsterdam University Press, Amsterdam, The Netherlands.

Lam, W. F. 1996. Institutional design of public agencies and coproduction: a case study of irrigations in Taiwan. World Development 24:1039-1054.

Ludwig, D., R. Hilborn, and C. Walters. 1993. Uncertainty, resource exploitation, and conservation: lessons from history. Science 260:17-36.

Mazrui, A. M., and I. Noor Shariff. 1994. The Swahili: idiom and identity of an African people. Africa World Press, Trenton, New Jersey, USA.

McCay, B. J. 2002. Emergence of Institutions for the commons: contexts, situations and events. Pages 361-402 in Ostrom, E., T. Dietz, N, Dolšak, P. C. Stern, S. Stovich, and E. U. Weber, editors. The drama of the commons. NRC Committee on the Human Dimensions of Global Change, Division of Behavioral and Social Sciences and Education. National Academy Press, Washington, D.C., USA.

Myers, G. 2002. Local communities and the new environmental planning: a case study from Zanzibar. Area 34:149-159.

Napier, V. R., G. M. Branch, and J. M. Harris 2005. Evaluating conditions for successful comanagement of subsistence fisheries in KwaZuluNatal, South Africa. Environmental Conservation 32:165-177.

Nielsen, J. R., P. Degnbol, K. K. Viswanathan, M. Ahmed, M. Hara, and N. K. Raja Abdullah. 2004. Fisheries co-managemen: an institutional innovation? Lessons from South East Asia and Southern Africa. Marine Policy 28:151-160.

Obura, D. O., S. Wells, J. Church, and C. Horrill. 2002. Monitoring of fish and fish catches by local fishermen in Kenya and Tanzania. Marine and Freshwater Research 53:215-222.

Olsson, P., C. Folke, and T. Hahn. 2004. Socialecological transformation for ecosystem management: the development of adaptive co-management of a wetland landscape in southern Sweden. Ecology and Society 9(4).

[online] URL: http://www.ecologyandsociety.org/vol9/ iss4/art2/.

Ostrom, E. 1990. Governing the commons: the evolution of institutions for collective action. Cambridge University Press, Cambridge, UK.

Ostrom, E. 1996. Crossing the great divide: coproduction, synergy, and development. World Development 24:1073-1087.

Ostrom, E. 2003. Doing institutional analysis: digging deeper than markets and hirerchies. Pages 819-848 in M. Claude and M. Shirley editors. Handbook of new institutional economics. Kluwer Academic, Dordrecht, The Netherlands.

Ostrom, E., L. Schroeder, and S. Wynne. 1993. Institutional incentives and sustainable development: infrastructure policies in perspective. Westview, Boulder, Colorado, USA.

Peterman, R. M. 2004. Possible solutions to some challenges facing fisheries scientists and managers. International Council for the Exploration of the Sea Journal of Marine Science 61:1331-1343.

Pomeroy, R.S., and F. Berkes. 1997. Two to tango: the role of government in fisheries co-management. Marine Policy 21:465-480.

Ruitenbeek, J., I. Hewawasam, and M. Ngoile, editors. 2005. Blueprint 2050: sustaining the marine environment in mainland Tanzania and Zanzibar. The International Bank for Reconstruction and Development, The World Bank, Washington, D. C., USA.

Scott, W. R. 2001. Institutions and organizations. Sage, New York, New York, USA.

Sheffer, M., S. Carpenter, and B. de Young. 2005. Cascading effects of overfishing marine systems. Trends in Ecology and Evolution 20: 579-581.

United Republic of Tanzania (URT). 1977. Constitution of the United Republic of Tanzania. URT, Zanzibar, Tanzania.

Western Indian Ocean Marine Scientists Association (WIOMSA). 2005. Fourth WIOMSA Scientific Symposium. Contribution of research in improving welfare and poverty alleviation. 30 
August-1 September 2005, Grand Baie, Mauritius.

Available online at: http://www.wiomsa.org.

Young, O. R. 2002. The institutional dimensions of environmental change. Massachusetts Institute of Technology, Cambridge, Massachusetts, USA. 